

\title{
Structure and Magnetic Properties of an Original Cu II Mn II W V Heterotrimetallic Coordination Polymer
} M.-G Alexandru, Diana Visinescu, Augustin M. Madalan, Rodolphe Clérac, Marius Andruh

\section{- To cite this version:}

M.-G Alexandru, Diana Visinescu, Augustin M. Madalan, Rodolphe Clérac, Marius Andruh. Structure and Magnetic Properties of an Original Cu II Mn II W V Heterotrimetallic Coordination Polymer. European Journal of Inorganic Chemistry, 2020, pp.3111-3114. 10.1002/ejic.202000469 hal-02928009

\section{HAL Id: hal-02928009 \\ https://hal.science/hal-02928009}

Submitted on 2 Sep 2020

HAL is a multi-disciplinary open access archive for the deposit and dissemination of scientific research documents, whether they are published or not. The documents may come from teaching and research institutions in France or abroad, or from public or private research centers.
L'archive ouverte pluridisciplinaire HAL, est destinée au dépôt et à la diffusion de documents scientifiques de niveau recherche, publiés ou non, émanant des établissements d'enseignement et de recherche français ou étrangers, des laboratoires publics ou privés. 


\title{
Structure and Magnetic Properties of an Original $\left\{\mathrm{Cu}^{\prime \prime} \mathrm{Mn}^{\prime \prime} \mathbf{W}^{\mathbf{v}}\right\}$ Heterotrimetallic Coordination Polymer
}

\author{
Maria-Gabriela Alexandru, ${ }^{[\mathrm{a}]}$ Diana Visinescu, ${ }^{[\mathrm{b}]}$ Augustin M. Madalan, ${ }^{[\mathrm{c}]}$ Rodolphe Clérac, ${ }^{*[\mathrm{~d}]}$ \\ and Marius Andruh*[c]
}

Dedicated to Professor Herbert W. Roesky, on the occasion of his $85^{\text {th }}$ birthday

Abstract: A monodimensional heterotrimetallic coordination polymer of formula ${ }_{1}^{\infty}\left[\left\{\mathrm{Cu}^{\prime \prime} \mathrm{Mn} n^{\prime \prime} \mathrm{L}^{2}\right\}_{3}\left\{(\mu-\mathrm{NC})_{3} \mathrm{~W}^{\mathrm{V}}(\mathrm{CN})_{5}\right\}_{2}\right] \cdot \mathrm{H}_{2} \mathrm{O}$ (1) has been assembled from pre-designed $\left[\mathrm{CU}^{\prime \prime} \mathrm{Mn} \mathrm{L}^{2}\right]^{2+}$ cationic modules and homoleptic $\left[\mathrm{W}^{\mathrm{V}}(\mathrm{CN})_{8}\right]^{3-}$ metalloligands $\left(\mathrm{H}_{2} \mathrm{~L}^{2}\right.$ is the compartmental Schiff-base resulting from the stepwise condensation of 2,6-diformyl-p-cresol with ethylenediamine and di- ethylenetriamine). The magnetic properties of $\mathbf{1}$ have been investigated revealing a three-dimensional ordered antiferromagnetic ground state below $4 \mathrm{~K}$ resulting from different antiferromagnetic interactions between all the spin carriers $\left(S=1 / 2 \mathrm{Cu}^{\prime \prime}\right.$, $S=5 / 2 \mathrm{Mn}^{\prime \prime}$, and $S=1 / 2 \mathrm{~W}^{\vee}$ centers).
Polynuclear complexes containing different paramagnetic metal ions are of high interest in molecule-based magnetism. ${ }^{[1]}$ The large majority of the heterometallic molecular systems are constructed from two different metal ions. Conversely, complexes with three different paramagnetic centers are significantly less common, mainly because of the difficulties related to the scrambling of the metal ions. ${ }^{[2]}$ A rational synthetic approach towards heterotrimetallic complexes consists of assembling preformed heterobimetallic modules and metalloligands. ${ }^{[2]}$ Anionic cyanido complexes, homo- and heteroleptic, are excellent metalloligands for building magnetic moleculebased materials containing two, or more, different metal ions. ${ }^{[3]}$ Our work in this field of research has been focused on the use of heterobimetallic tectons like phenoxido-bridged $3 d-3 d^{\prime}$ and $3 \mathrm{~d}-4 \mathrm{f}$ complexes, with the metal ions enclosed into different coordination sites generated by dissymmetric macrocyclic or

[a] Dr. M.-G. Alexandru

Department of Inorganic Chemistry, Physical Chemistry and

Electrochemistry, Faculty of Applied Chemistry and Materials Science,

University Politehnica of Bucharest,

1-7 Gh. Polizu Street, 01106, Bucharest, Romania

[b] Dr. D. Visinescu

Coordination and Supramolecular Chemistry Laboratory, "llie Murgulescu" Institute of Physical Chemistry, Romanian Academy,

Splaiul Independentei 202, Bucharest-060021, Romania

[c] Dr. A. M. Madalan, Prof. Dr. M. Andruh

Inorganic Chemistry Laboratory, Faculty of Chemistry, University of Bucharest,

Str. Dumbrava Rosie 23, 020464- Bucharest, Romania

E-mail: marius.andruh@dnt.ro

[d] Dr. R. Clérac

Univ. Bordeaux, CNRS, Centre de Recherche Paul Pascal, UMR 5031,

33600 Pessac, France

E-mail: clerac@crpp-bordeaux.cnrs.fr side-off compartmental ligands. ${ }^{[4]}$ Indeed, most of the known heterotrimetallic complexes are assembled using $3 \mathrm{~d}-4 \mathrm{f}$ precursors, which are easily obtained by exploiting the differences between $3 \mathrm{~d}$ and $4 \mathrm{f}$ metal ions [coordination numbers, HSAB "hard and soft (Lewis) acids and bases" - behavior] and using side-off compartmental ligands. ${ }^{[5]}$ The synthesis of $3 d-3 d^{\prime}$ magnetic building-blocks is more delicate, since the differences mentioned above are less prominent. One appropriate pair is composed of $\mathrm{Cu}^{\prime \prime}$ and $\mathrm{Mn}^{\prime \prime}$ ions, especially because $\mathrm{Mn}^{\prime \prime}$ does not have a particular stereochemical preference, while $\mathrm{Cu}^{\prime \prime}$ does. Robust binuclear Cu"-Mn" complexes have been generated using side-off compartmental ligands (like $\mathrm{H}_{2} \mathrm{~L}^{1}$ see Scheme 1) with an open compartment that allows various coordination numbers and geometries for the $\mathrm{Mn}^{\text {"l }}$ ion, while the inner compartment hosts a Cu" metal ion with a square-planar or squarepyramidal geometry (Scheme 1). ${ }^{[6]}$

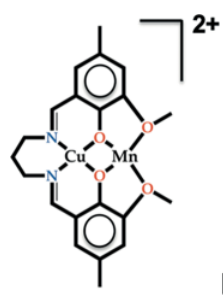

$\left[\mathrm{CuMnL}{ }^{1}\right]^{2+}$

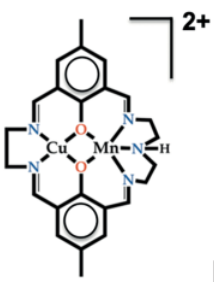

$[\mathrm{CuMnL}]^{2+}$

Scheme 1.

For analogous bis-phenoxido-bridged Cu"-Mn" binuclear complex, $\left[\mathrm{Cu}^{\prime \prime} \mathrm{Mn} \mathrm{L}^{2}\right]^{2+}$ (Scheme 1), the metal ions are held together by a dissymmetric compartmental Robson-type ligand. ${ }^{[7]}$ Both binuclear systems are characterized by an $S=2$ ground state, which results from a significant antiferromagnetic interaction between $S=1 / 2 \mathrm{Cu}^{\prime \prime}$ and $S=5 / 2 \mathrm{Mn}^{\prime \prime}$ centers, and are thus good building-block candidates for designing heterotrimetallic magnetic complexes and networks. For example, the self-as- 


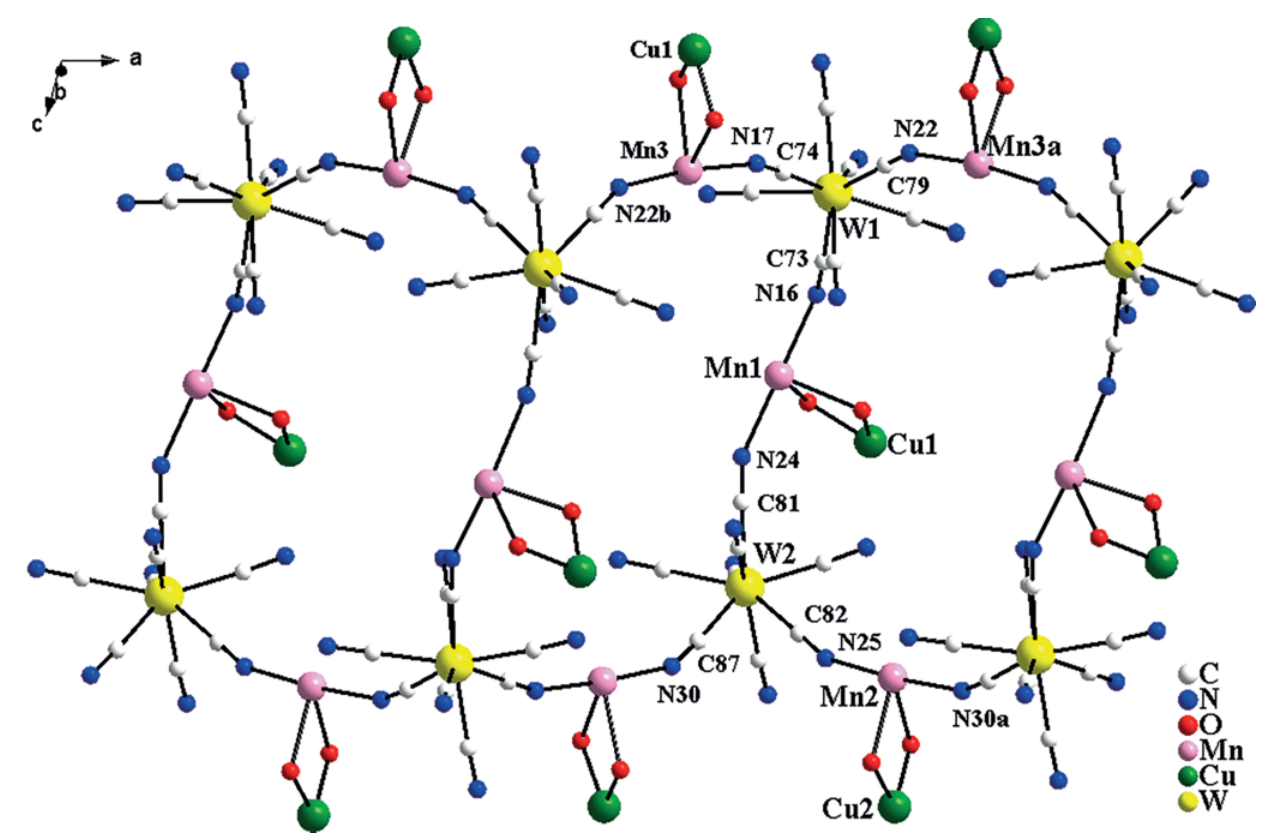

Figure 1. View of the crystal structure of $\mathbf{1}$ emphasizing the one-dimensional coordination polymer running along the $a$ axis (symmetry operations: a $=0.5+$ $x, 0.5-y, z ; b=-0.5+x, 0.5-y, z)$

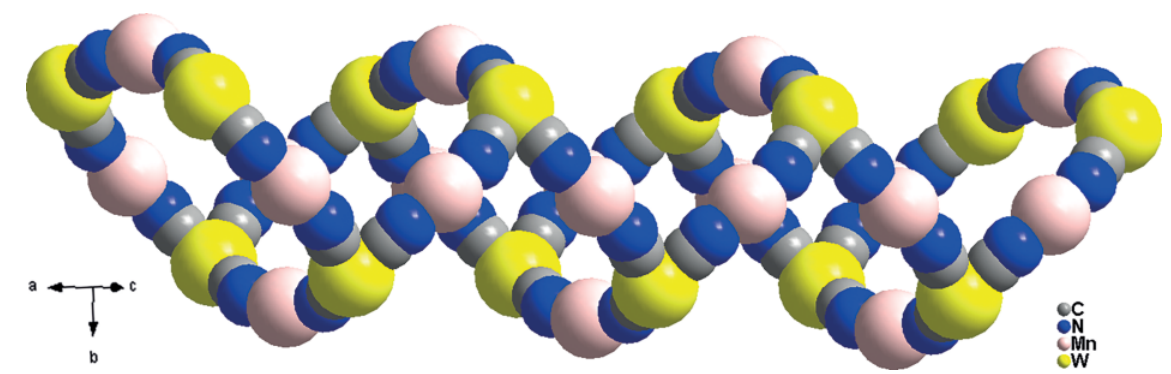

Figure 2. Perspective view of a wavy/accordion-like chain in 1 resulting from fused octanuclear $\left\{\mathrm{Cu}^{\prime \prime}-\mathrm{NC}-\mathrm{W}^{\mathrm{V}}-\mathrm{CN}\right\}_{4}$ metallacycles.

sembly of $\left.\left[\mathrm{Cu}^{\prime \prime} \mathrm{Mn} \mathrm{L}^{\prime \prime}\right]^{1}\right]^{2+}$ and $\left[\mathrm{Cr}^{\prime \prime \prime}(\mathrm{ampy})(\mathrm{CN})_{4}\right]^{-}$modules (ampy = aminomethylpyridine) results in a 2-D 3d-3d'-3d" network which possess a ferrimagnetic state below $4.3 \mathrm{~K}^{[6 \mathrm{~b}]}$ So far, only three heterotrimetallic chains, $\left[\mathrm{Cu}^{\prime \prime} \mathrm{Mn}^{\prime \prime} \mathrm{L}^{2} \mathrm{M}^{\prime \prime \prime}\right]_{n}(\mathrm{M}=\mathrm{Fe}$, $\mathrm{Cr})^{[7 \mathrm{a}]}$ and $\left[\mathrm{Cu}^{\prime \prime} \mathrm{Mn}{ }^{\prime \prime} \mathrm{L}^{2} \mathrm{~W}^{\mathrm{V}}\right]_{n}{ }^{[\mathrm{7b}]}$ have been reported and obtained starting from $\left[\mathrm{Cu}^{\prime \prime} \mathrm{Mn} \mathrm{L}^{2}\right]^{2+}$ and heteroleptic cyanido metalloligands.

Herein, we are adding a new member to the small family of the $3 d-3 d^{\prime}-3(4,5) d^{\prime \prime}$ complexes. This coordination polymer, ${ }_{1}^{\infty}\left[\left\{\mathrm{Cu}^{\prime \prime} \mathrm{Mn} \mathrm{L}^{\prime \prime} \mathrm{L}^{2}\right\}_{3}\left\{(\mu-\mathrm{NC})_{3} \mathrm{~W}^{\mathrm{V}}(\mathrm{CN})_{5}\right\}_{2}\right] \cdot \mathrm{H}_{2} \mathrm{O}(\mathbf{1})$, which shows a very original one-dimensional topology, is obtained by layering equimolar acetonitrile solutions of $\left[\mathrm{Cu}^{\prime \prime} \mathrm{Mn}^{\prime \prime} \mathrm{L}^{2}\right]\left(\mathrm{ClO}_{4}\right)_{2}$ and $\left(\mathrm{NHBu}_{3}\right)_{3}\left[\mathrm{~W}^{\vee}(\mathrm{CN})_{8}\right]$ complexes (Supporting Information).

Compound 1 crystallizes in the monoclinic $P 2_{1} / a$ space group. Its structure consists of neutral one-dimensional coordination polymer (Figure 1) and crystallization water molecules. The asymmetric unit is formed by three binuclear $\left\{\mathrm{Cu}^{\prime \prime} M n^{\prime \prime} L^{2}\right\}$ nodes and two $\left\{\mathrm{W}^{\mathrm{V}}(\mathrm{CN})_{8}\right\}$ spacers, each one connecting three binuclear units, through three cyanido groups (Figures 1 and S1, crystallographic details are given in Tables S1 and S2, CCDC 2000465). The resulting coordination network forms octanu- clear $\left\{\mathrm{Cu}^{\mathrm{II}}-\mathrm{NC}-\mathrm{W}^{\mathrm{V}}-\mathrm{CN}\right\}_{4}$ metallacycles which are fused to form a wavy/accordion-like chain (Figure 2) running along the crystallographic $a$ direction.

Both crystallographically independent W1 and W2 metal ions are coordinated by eight cyanido carbon atoms building a distorted square antiprism and a distorted dodecahedron geometry, respectively, according to SHAPE 2.1 calculations (Fig. S2, Table S3). ${ }^{[8]}$ The $\left\{\mathrm{W} 1(\mathrm{CN})_{8}\right\}$ spacer is connected, through the cyanido ligands, to $\mathrm{Mn} 1, \mathrm{Mn} 3$ and $\mathrm{Mn3a}$ atoms from the $\left\{\mathrm{Cu}^{\prime \prime} M n^{\prime \prime} \mathrm{L}^{2}\right\}$ modules. The second cyanido metalloligand, $\left\{\mathrm{W} 2(\mathrm{CN})_{8}\right\}$, also adopts a tris-monodentate coordination mode to $M n 1, M n 2$, and Mn2b. Each of the three crystallographically independent binuclear modules contains one $\mathrm{Cu}^{\prime \prime}$ ion, placed into the $\left\{\mathrm{N}_{2} \mathrm{O}_{2}\right\}$ compartment, and one $\mathrm{Mn}^{\prime \prime}$ ion into the larger $\left\{\mathrm{N}_{3} \mathrm{O}_{2}\right\}$ compartment of the Schiff-base ligand. The copper(II) atoms are tetracoordinated by two imino nitrogen atoms [the shortest and longest bond lengths being 1.885(9) ^̊ for Cu3N12, and 1.929(10) Å for Cu3-N11], and by two phenoxido oxygen atoms [the shortest and longest bond lengths being

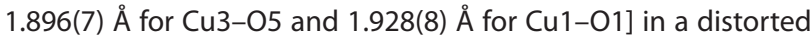
square planar environment (Table S2). ${ }^{[8]}$ Focusing now on the 
di-phenoxido bridged $\left\{\mathrm{Cu}^{\prime \prime} \mathrm{Mn}^{\prime \prime}\right\}$ fragment, the distances between the metal ions are: $3.249 \AA$ for Cu1...Mn1, $3.298 \AA$ for Cu2...Mn2, and $3.287 \AA$ for Cu3...Mn3. The angles at the bridging phenoxido atoms have values of 99.3(3)-101.8(3) for Cu1O1(O2)-Mn1, 101.6(3)-100.9(3) for Cu2-O3(O4)-Mn2, and 101.6(3)-101.7(3) ${ }^{\circ}$ for Cu3-O5(O6)-Mn3. The Mn" ions are heptacoordinated by two oxygen atoms [the shortest and longest bond lengths being 2.267(8) A for Mn1-O2 and 2.351(8) for $\mathrm{Mn2}-\mathrm{O} 4]$, and by three nitrogen atoms belonging to the $\left\{\mathrm{N}_{3} \mathrm{O}_{2}\right\}$ compartment of the Schiff base ligand [the shortest and longest bond lengths being 2.244(11) $\AA$ for Mn2-N8 and 2.389(12) $\AA ̊$ for Mn3-N14], and by two cyanido-nitrogen atoms from two $\left\{\mathrm{W}^{\mathrm{V}}(\mathrm{CN})_{8}\right\}$ units. Their coordination geometries, determined using SHAPE 2.1 program, are capped trigonal prism for Mn1, and pentagonal bipyramid for Mn2 and Mn3 (Fig. S3, Table S3). The $\mathrm{Mn}-\mathrm{N}_{\text {cyanide }}$ bond lengths are: 2.421(11) and 2.242(10) $\AA$ for Mn1-N16 and Mn1-N24, respectively; 2.276(10) and 2.279(10) $\AA$ for Mn2-N25 and Mn2-N30a; 2.286(10) and 2.272(10) $\AA$ for Mn3-N17 and Mn3-N22b (symmetry operations: $a=0.5+x$, $0.5-y, z ; b=-0.5+x, 0.5-y, z)$. The most relevant angles involving the cyanido bridging ligands are: 152.4(10) and 159.1(10) for Mn1-N24-C81 and Mn1-N16-C73; 159.1(10) and $154.4(8)^{\circ}$ for Mn2-N25-C82 and Mn2-N30a-C87a; 161.0(10) and $153.4(9)^{\circ}$ for Mn3-N17-C74 and Mn3-N22b-C79b. Selected bond lengths and angles are gathered in Table S2. The geometrical parameters concerning the $\left\{\mathrm{Cu}^{\prime \prime} \mathrm{Mn}{ }^{\prime \prime} \mathrm{L}\right\}$ fragment are in agreement with similar reported examples. ${ }^{[7 b]}$ The close inspection of the packing diagram reveals hydrogen bonds connecting the double chains as shown in Figures S4 and S5.

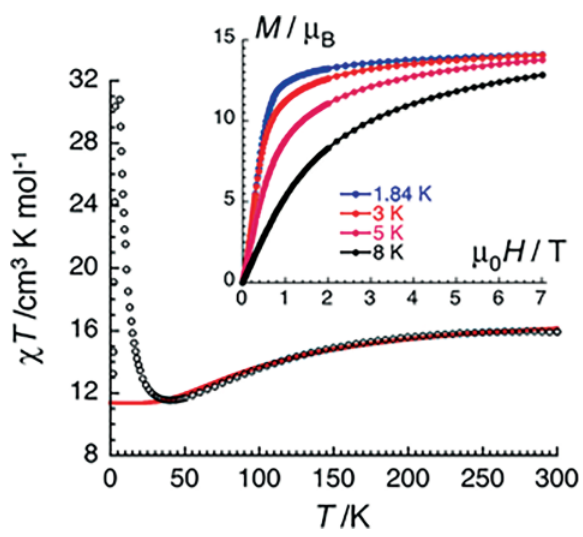

Figure 3. Temperature dependence of the $\chi^{T}$ product for 1 at $0.1 \mathrm{~T}$ applied dc fields ( $\chi$ is defined as $M / H$ per mole of 1 ). Inset: Field dependence of the magnetization at indicated temperature with field sweep rates of 100 400 Oe $\mathrm{min}^{-1}$ for $\mu_{0} H<1 \mathrm{~T}$ and 500-2500 Oe $\mathrm{min}^{-1}$ for $\mu_{0} H>1 \mathrm{~T}$.

The dc magnetic susceptibility has been measured for 1 between 1.85 and $300 \mathrm{~K}$ with magnetic field up to $7 \mathrm{~T}$ (Figure 3 and Figure 4). Consistent dc susceptibility at $0.1 \mathrm{~T}$ and in-phase ac susceptibility in zero-dc field (with an ac frequency of $1000 \mathrm{~Hz}$ ) have been obtained between 1.85 and $15 \mathrm{~K}$ without detection of an out-of-phase ac signal, Figure S6. The $\chi T$ product at room temperature is $15.9 \mathrm{~cm}^{3} \mathrm{~K} \mathrm{~mol}^{-1}$, which is perfectly consistent with the 3:3:2 $\mathrm{Cu}^{\prime \prime} / \mathrm{Mn}^{\prime \prime} / \mathrm{W}^{V}$ stoichiometry of the ${ }_{1}\left[\left\{\mathrm{Cu}^{\prime \prime} \mathrm{Mn} \mathrm{L}^{\prime \prime}\right\}_{3}\left\{(\mu-\mathrm{NC})_{3} \mathrm{~W}^{\vee}(\mathrm{CN})_{5}\right\}_{2}\right] \cdot \mathrm{H}_{2} \mathrm{O}$ complex, the three differ-
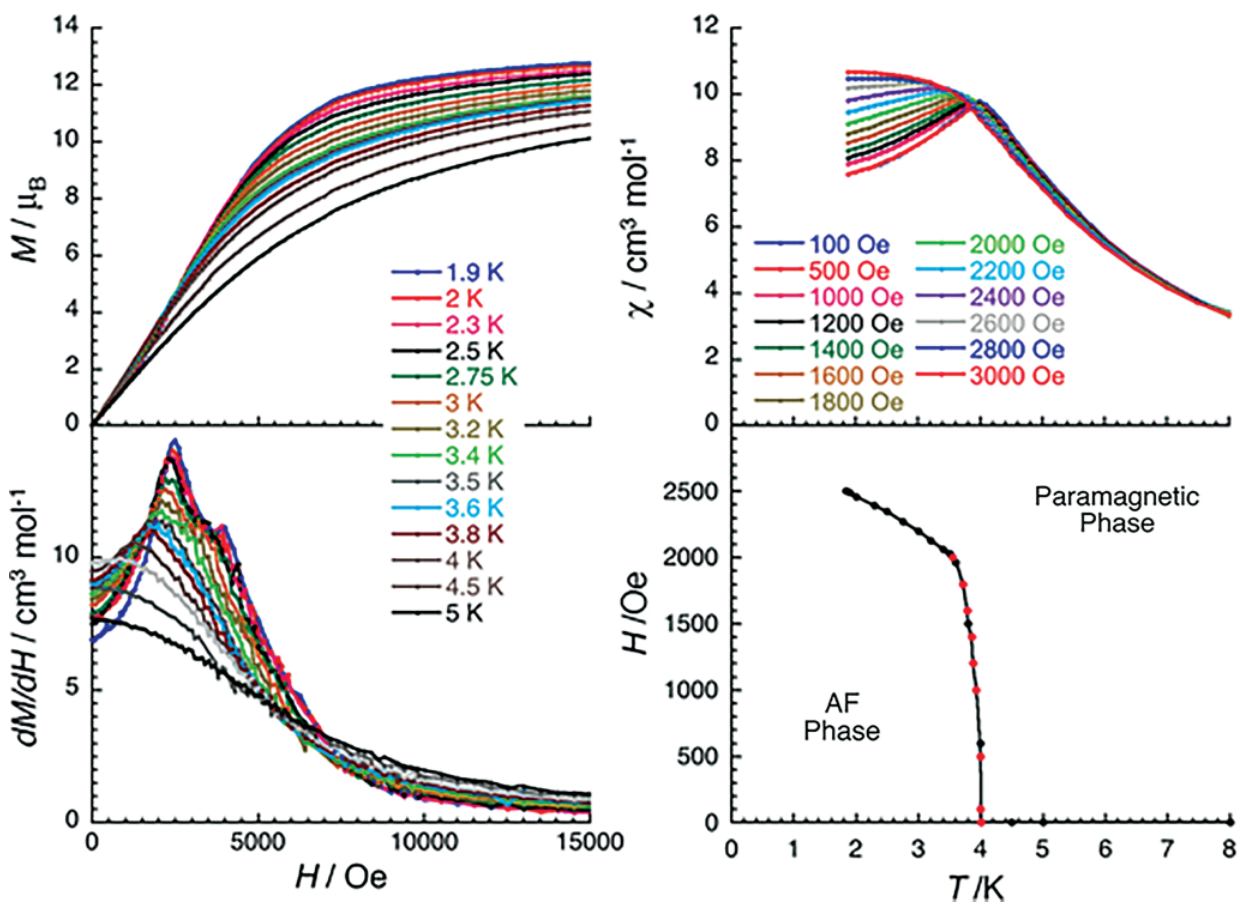

Figure 4. Low temperature magnetic properties for 1: (top left) $M$ vs. $H$ and (bottom left) $\mathrm{d} M / \mathrm{d} H$ vs. $H$ plots with field sweep rates of $100-200$ Oe min ${ }^{-1}$; (top right) $\chi$ vs. $T$ plots; and (bottom right) magnetic phase diagram $(H, T)$ constructed from $\chi$ vs. $T$ (red) and $M$ vs. $H$ (black) data. Solid lines are visual guides for the eye. 
ent types of paramagnetic centers $(S=1 / 2 / S=5 / 2 / S=1 / 2)$, and the expected Curie constant of $15 \mathrm{~cm}^{3} \mathrm{~K} \mathrm{~mol}^{-1}$ with $C_{\mathrm{Cu}}=$ $0.375 \mathrm{~cm}^{3} \mathrm{~K} \mathrm{~mol}^{-1}, C_{\mathrm{Mn}}=4.375 \mathrm{~cm}^{3} \mathrm{~K} \mathrm{~mol}^{-1}$ and $C_{\mathrm{W}}=$ $0.375 \mathrm{~cm}^{3} \mathrm{~K} \mathrm{~mol}^{-1}$ with an average $g$ value of 2.0. The decrease of the $\chi^{T}$ product upon lowering the temperature down to $11.5 \mathrm{~cm}^{3} \mathrm{~K} \mathrm{~mol}^{-1}$ at $40 \mathrm{~K}$ reveals the strongest antiferromagnetic interactions in $\mathbf{1}$ that are located between $S=1 / 2 \mathrm{Cu}^{\text {II }}$ and $S=5 / 2 \mathrm{Mn}^{\prime \prime}$ magnetic centers within the $\left[\mathrm{Cu}^{\prime \prime} \mathrm{Mn}^{\prime \prime} \mathrm{L}^{2}\right]^{2+}$ module as already observed with similar systems. The double-phenoxido-bridge is expected to mediate significant antiferromagnetic interaction, $J / k_{\mathrm{B}}$, between $\mathrm{Cu}^{\prime \prime}$ and $\mathrm{Mn}^{\prime \prime}$ spins of the order of -22 to $-53 \mathrm{~K}$ with $\boldsymbol{H}=-2 \boldsymbol{J} \boldsymbol{S}_{\mathrm{Cu}} \boldsymbol{S}_{\mathrm{Mn}} \cdot{ }^{[6 b, 6 c, 9]}$ Using this Heisenberg heterospin Hamiltonian for the three $\left[\mathrm{Cu}^{\prime \prime} \mathrm{Mn}^{\prime \prime} \mathrm{L}^{2}\right]^{2+}$ modules and treating the two $S=1 / 2 W^{V}$ centers as Curie-type spins, the experimental data down to $40 \mathrm{~K}$ can be well fitted allowing an estimation of $J / k_{B}$ at $-27(1) \mathrm{K}$ with an average $g$ factor of 2.17(5) (see solid red line in Figure 3). At lower temperatures, the $\chi T$ product variation is the consequence of the smaller magnetic interactions which become relevant between the $S=1 / 2 W^{V}$ and $S=5 / 2 \mathrm{Mn}^{\prime \prime}$ spins through cyanido bridges, as well as weaker dipolar interactions. Below $40 \mathrm{~K}$, the increase of the $\chi T$ product (up to $31 \mathrm{~cm}^{3} \mathrm{~K} \mathrm{~mol}^{-1}$ at $4.5 \mathrm{~K}$ ) highlights the noncompensation of the metal ion spins and the growth of the magnetic correlations in the material. Below $4.5 \mathrm{~K}$, the decrease of the $\chi T$ product indicates the stabilization of an ordered antiferromagnetic state as demonstrated by the combined $\chi$ vs. $T$ and $M$ vs. $H$ data shown in Figure 4 .

The $M$ vs. $H$ data below $4 \mathrm{~K}$ show an inflection point at low fields below 3000 Oe, which is clearly detected on the $d M / d H$ vs. $H$ plots (Figure 4). This critical field, $H_{C}(2500$ Oe at $1.85 \mathrm{~K})$, can be followed increasing temperature up to $4 \mathrm{~K}$ where it vanishes as expected in the case of a magnetic phase transition. Concomitantly, the dc magnetic susceptibility at a fixed dc field exhibits a maximum around $4 \mathrm{~K}$ corresponding to the Néel Temperature, $T_{\mathrm{N}}$. The temperature dependence of $H_{\mathrm{C}}$ and the field dependence of $T_{\mathrm{N}}$ can be obtained from the $\mathrm{d} M / \mathrm{d} H$ vs. $H$ and $\chi$ vs. $T$ data, respectively, in order to determine the $(T, H)$ magnetic phase diagram shown in Figure 4 . The topology of this phase diagram is typical of a metamagnetic material exhibiting a $3 \mathrm{D}$ ordered antiferromagnetic ground state. In the saturated paramagnetic state (Figure 3 inset) at high field, the magnetization at $1.85 \mathrm{~K}$ saturates above $5 \mathrm{~T}$ to about $14 \mu_{\mathrm{B}}$ in agreement with the field alignment of the three $S=2\left[\mathrm{Cu}^{\prime \prime} \mathrm{Mn}^{\prime \prime} \mathrm{L}^{2}\right]^{2+}$ units and two $S=1 / 2 W^{V}$ spins.

This molecule-based chemistry using pre-designed magnetic modules can be easily extended using other metalloligands, as well ancillary bridging ligands, in order to obtain new trimetallic networks with various dimensionalities and topologies incorporating larger magnetic interactions in order to stabilize high $T_{\mathrm{C}}$ magnets. Further work in these directions is currently in progress in our laboratories.

Deposition Number 2000465 (for 1) contains the supplementary crystallographic data for this paper. These data are provided free of charge by the joint Cambridge Crystallographic Data Centre and
Fachinformationszentrum Karlsruhe Access Structures service www.ccdc.cam.ac.uk/structures.

\section{Acknowledgments}

The work was supported by: UEFISCDI (grant number PNII-IDPCCE-2011-2-0050), by the CNRS, University of Bordeaux, the Région Nouvelle Aquitaine, and the MOLSPIN COST action CA15128 and the GdR MCM-2.

[1] a) N. Roques, V. Mugnaini, J. Veciana, Top. Curr. Chem. 2010, 293, 207; b) J. S. Miller, Chem. Soc. Rev. 2011, 40, 3266; c) P. Dechambenoit, J. R. Long, Chem. Soc. Rev. 2011, 40, 3249; d) I.-R. Jeon, R. Clérac, Dalton Trans. 2012 41, 9569; e) A. Caneschi, D. Gatteschi, F. Totti, Coord. Chem. Rev. 2015, 289, 357; f) D. Aguilà, Y. Prado, E. S. Koumousi, C. Mathonière, R. Clérac, Chem. Soc. Rev. 2016, 45, 203; g) J. Ferrando-Soria, J. Vallejo, M. Castellano, J. Martínez-Lillo, E. Pardo, J. Cano, I. Castro, F. Lloret, R. Ruiz-García, M. Julve, Coord. Chem. Rev. 2017, 339, 17.

[2] M. Andruh, Chem. Commun. 2018, 54, 3559.

[3] a) K. S. Lim, C. S. Hong, Dalton Trans. 2013, 42, 14941; b) Y.-H. Li, W.-R. He, X.-H. Ding, S. Wang, L.-F. Cui, W. Huang, Coord. Chem. Rev. 2012, 256, 2795; c) M.-G. Alexandru, D. Visinescu, N. Marino, G. De Munno, J. Vallejo, F. Lloret, M. Julve, Eur. J. Inorg. Chem. 2014, 4564; d) D. Pinkowicz, R Podgajny, B. Nowicka, S. Chorazy, M. Reczyński, B. Sieklucka, Inorg. Chem. Front. 2015, 2, 10.

[4] a) M. Andruh, D. G. Branzea, R. Gheorghe, A. M. Madalan, CrystEngComm 2009, 11, 2571; b) M. Andruh, Chem. Commun. 2011, 47, 3025; c) M. Andruh, Dalton Trans. 2015, 44, 16633.

[5] a) D. Visinescu, A. M. Madalan, M. Andruh, C. Duhayon, J.-P. Sutter, L. Ungur, W. Van de Heuvel, L. F. Chibotaru, Chem. Eur. J. 2009, 15, 11808; b) R. Gheorghe, A. M. Madalan, J.-P. Costes, W. Wernsdorfer, M. Andruh, Dalton Trans. 2010, 39, 4734; c) M.-G. Alexandru, D. Visinescu, A. M. Madalan, F. Lloret, M. Julve, M. Andruh, Inorg. Chem. 2012, 51, 4906; d) M.-G. Alexandru, D. Visinescu, M. Andruh, N. Marino, D. Armentano, J. Cano, F. Lloret, M. Julve, Chem. Eur. J. 2015, 21, 5429; e) D. Visinescu, M.-G. Alexandru, A. M. Madalan, I.-R. Jeon, C. Mathonière, R. Clérac, M. Andruh, Dalton Trans. 2016, 45, 7642; f) V. Vieru, T. D. Pasatoiu, L. Ungur, E. Suturina, A. M. Madalan, C. Duhayon, J.-P. Sutter, M. Andruh, L. F. Chibotaru, Inorg. Chem. 2016, 55, 12158; g) M.-J. Liu, K.-Q. Hu, C.-M. Liu, A.-L. Cui, H.-Z. Kou, Dalton Trans. 2017, 46, 6544; h) H. Zhou, R. Dong, Z. Wang, L. Wu, Y. Liu, X. Shen, Eur. J. Inorg. Chem. 2019, 2361; i) A. Dogaru, J.-L. Liu, G. Marinescu, R. Clérac, M. Andruh, Polyhedron 2020, 175, 114242.

[6] a) D.-G. Branzea, A. Guerri, O. Fabelo, C. Ruiz-Pérez, L.-M. Chamoreau, C. Sangregorio, A. Caneschi, M. Andruh, Cryst. Growth Des. 2008, 8, 941; b) M.-G. Alexandru, D. Visinescu, S. Shova, F. Lloret, M. Julve, Inorg. Chem. 2017, 56, 2258; c) M.-G. Alexandru, D. Visinescu, S. Shova, M. Andruh, F. Lloret, J. Cano, M. Julve, Dalton Trans. 2018, 47, 1010.

[7] a) H. Wang, L.-F. Zhang, Z.-H. Ni, W.-F. Zhong, L.-J. Tian, J. Jiang, Cryst. Growth Des. 2010, 10, 4231; b) M.-G. Alexandru, D. Visinescu, S. Shova, M. Andruh, F. Lloret, M. Julve, Eur. J. Inorg. Chem. 2018, 360.

[8] a) M. Llunell, D. Casanova, J. Cirera, J. M. Bofill, P. Alemany, S. Alvarez M. Pinsky, D. Avnir, SHAPE: Continuous shape measures of polygonal and polyhedral molecular fragments, 1.1b, University of Barcelona, Barcelona, 2005; b) D. Casanova, M. Llunell, P. Alemany, S. Alvarez, Chem. Eur. J. 2005, 11, 1479.

[9] a) A. Biswas, L. Mandal, S. Mondal, C. R. Lucas, S. Mohanta, CrystEngComm 2013, 15, 5888; b) D. G. Branzea, A. M. Madalan, S. Ciattini, N. Avarvari, A. Caneschi, M. Andruh, New J. Chem. 2010, 34, 2479. 


\section{Supporting Information}

Structure and Magnetic Properties of an Original $\left\{\mathrm{Cu}^{\prime \prime} \mathrm{Mn}^{\prime \prime} \mathrm{W}^{\mathrm{V}}\right\}$ Heterotrimetallic Coordination Polymer

Maria-Gabriela Alexandru, Diana Visinescu, Augustin M. Madalan, Rodolphe Clérac, ${ }^{*}$ and Marius Andruh* 


\section{Experimental part}

Table S1. Crystal data and details of structure determination for compound $\mathbf{1 .}$

Table S2. Bond Lengths ( $⿱$ ) and angles (deg) of the environments of the copper(II), manganese(II) and tungsten $(\mathrm{V})$ ions in $\mathbf{1}$.

Figure S1. View of the asymmetric unit of $\mathbf{1}$ along with the atom numbering scheme.

Table S3. Results of the SHAPE1 analysis for the $\left[\mathrm{W}(\mathrm{CN})_{8}\right],\left[\mathrm{MnO}_{2} \mathrm{~N}_{5}\right]$ and $\left[\mathrm{CuO}_{2} \mathrm{~N}_{2}\right]$ fragments.

Figure S2. Coordination sphere of the $\mathrm{W}$ metal ion illustrating the distorted square antiprism coordination geometry for W1 and trigonal dodecahedron for W2 in $\mathbf{1}$.

Figure S3. Coordination sphere of the Mn1, Mn2 and Mn3 sites in 1.

Figure S4. Supramolecular interactions: fragment of the crystal structure of $\mathbf{1}$ highlighting the hydrogen bond network established between the water molecules and the heterotrimetallic chains.

Figure S5. Supramolecular interactions: chains running along $a$ axis, connected by hydrogen bonds shown in Figure S4.

Figure S6. Temperature dependence in zero-dc field of the in-phase and out-of-phase components of ac susceptibility (blue dots) for $\mathbf{1}$.

\section{References}




\section{Experimental part}

Materials. The chemicals and solvents used were of reagent grade and they were purchased from commercial sources. The starting compounds, $\left[\mathrm{Cu}^{\mathrm{II}} \mathrm{Mn}^{\mathrm{II}} \mathrm{L}\right]\left(\mathrm{ClO}_{4}\right)_{2} \cdot \mathrm{H}_{2} \mathrm{O} \cdot \mathrm{MeOH},{ }^{1-3}$ and $(n$ $\left.\mathrm{Bu}_{3} \mathrm{NH}\right)_{3}\left[\mathrm{~W}(\mathrm{CN})_{8}\right],{ }^{4}$ were synthesized by following the literature procedures $\left(n-\mathrm{Bu}_{3} \mathrm{NH}^{+}=\right.$tributyl ammonium cation).

Synthesis of ${ }^{\infty}\left[\left\{\mathbf{C u}^{\mathrm{II}} \mathbf{M n}^{\mathrm{II}} \mathbf{L}\right\}_{3}\left\{(\boldsymbol{\mu}-\mathrm{NC})_{3} \mathbf{W}^{\mathrm{V}}(\mathbf{C N})_{5}\right\}_{2}\right] \cdot \mathbf{H}_{2} \mathrm{O}(\mathbf{1})$. A solution of $\left(\mathrm{nBu}_{3} \mathrm{NH}\right)_{3}\left[\mathrm{~W}(\mathrm{CN})_{8}\right](20$ $\mathrm{mg}, 0.02 \mathrm{mmol})$ in acetonitrile $\left(15 \mathrm{~cm}^{3}\right)$ was poured slowly into an acetonitrile solution $\left(20 \mathrm{~cm}^{3}\right)$ containing $16 \mathrm{mg}[\mathrm{CuMnL}]\left(\mathrm{ClO}_{4}\right)_{2} \cdot \mathrm{H}_{2} \mathrm{O} \cdot \mathrm{CH}_{3} \mathrm{OH}(0.02 \mathrm{mmol})$. The resulting purple solution was left undisturbed for one week. X-ray quality purple crystals were obtained. Yield: $c a$. $70 \%$. Anal. Calcd for $\mathrm{C}_{88} \mathrm{H}_{83} \mathrm{Cu}_{3} \mathrm{~N}_{31} \mathrm{Mn}_{3} \mathrm{O}_{7} \mathrm{~W}_{2}$ (1): C, 43.82; H, 3.44; N, 18.01\%. Found: C, 43.45; H, 3.39; N, 18.37\%. IR $\left(\mathrm{KBr}, \mathrm{cm}^{-1}\right): 3340 \mathrm{~m}, v(\mathrm{C} \equiv \mathrm{N}): 2120 \mathrm{~s}, v(\mathrm{C}=\mathrm{N}): 1635 \mathrm{~m}, 1607 \mathrm{~m}, 1473 \mathrm{~s}, 1304 \mathrm{~m}, 1223 \mathrm{~s}, 1073 \mathrm{~m}$, $742 \mathrm{~m}$.

\section{Physical measurements}

Elemental analysis was carried out using a EuroVector model EA3000 CHNS elemental analyzer. The IR spectrum of $\mathbf{1}$ was recorded on a FTIR Bruker Tensor V-37 spectrophotometer using $\mathrm{KBr}$ pellets in the $4000-400 \mathrm{~cm}^{-1}$ range at room temperature. Magnetic measurements were carried out with a Quantum Design SQUID magnetometer MPMS-XL. This magnetometer works between 1.8 and $400 \mathrm{~K}$ for dc applied fields ranging from -7 to $7 \mathrm{~T}$. Ac susceptibility measurements were performed with a Quantum Design PPMS-9 susceptometer working with an oscillating ac field of 1 Oe with a frequency between 10 and $10000 \mathrm{~Hz}$. These magnetic measurements were performed on a microcrystalline sample sealed in a polyethylene bag ( $3 \AA \sim 0.5 \AA \sim 0.02 \mathrm{~cm}$; typical mass of 15-30 $\mathrm{mg}$ ). Magnetic data were corrected for the sample holder and diamagnetic contributions for all magnetic measurements.

\section{Crystallographic data collection and structure determination}

Suitable single crystals of compound $\mathbf{1}$ were mounted on an IPDS II STOE diffractometer. Diffraction data for compound 1 were collected at 293(2) K using graphite-monochromated Mo-K $\alpha$ radiation $(\lambda=0.71073 \AA)$. Multiscan absorption corrections were applied. The structures were solved by direct methods using SHELXS-2014 and refined by means of least squares procedures using SHELXL-2018. Atomic scattering factors were taken from the international tables for X-ray crystallography. The hydrogen atoms of the organic ligand were refined using a riding model, although most of the water hydrogen atoms were refined freely (geometrical restraints were used for the refinement of some of them). Drawings of the molecule were performed with the program Diamond 4. A summary of the crystallographic data and the structure refinement is given in Table S1. CCDC reference number: 2000465. 
Table S1. Crystal data and details of structure determination for compound $\mathbf{1 .}$

\begin{tabular}{cc}
\hline Formula & $\mathrm{C}_{88} \mathrm{H}_{83} \mathrm{~N}_{31} \mathrm{O}_{7} \mathrm{Cu}_{3} \mathrm{Mn}_{3} \mathrm{~W}_{2}$ \\
Formula weight & 2409.99 \\
$T(\mathrm{~K})$ & $293(2)$ \\
Crystal system & Monoclinic \\
Space group & $P 2_{1} / a$ \\
$a(\overline{\mathrm{A}})$ & $14.6629(6)$ \\
$b(\overline{\mathrm{A}})$ & $29.3757(14)$ \\
$c(\mathrm{~A})$ & $22.7532(9)$ \\
$\beta\left({ }^{\circ}\right)$ & $105.685(3)$ \\
$V\left(\mathrm{~A}^{3}\right)$ & $9435.6(7)$ \\
$Z$ & 4 \\
$D_{\text {calcd }}\left(\mathrm{g} \cdot \mathrm{cm}^{-3}\right)$ & 1.697 \\
$\mu\left(\mathrm{mm}{ }^{-1}\right)$ & 3.548 \\
Goodness-of-fit, $S$ & 0.960 \\
${ }^{a}$ Final $R$ indices & $R_{1}=0.0704$ \\
{$[I \geq 2 \sigma(I)]^{\mathrm{a}}$} & $w R_{2}=0.1469$ \\
${ }^{b} R$ indices $(\text { all data })^{\mathrm{b}}$ & $R_{1}=0.1383$ \\
& $w R_{2}=0.1682$ \\
\hline
\end{tabular}

${ }^{[\mathrm{a}]} R_{1}=\sum\left|\left(\left|F_{0}\right|-\left|F_{c}\right|\right) / \sum\right| F_{c} \mid \cdot{ }^{[\mathrm{b}]} \mathrm{w} R_{2}=\left\{\sum\left[\mathrm{w}\left(F_{0}^{2}-F_{c}^{2}\right)^{2}\right] / \sum\left[\mathrm{w}\left(F_{0}^{2}\right)^{2}\right]\right\}^{0.5}$ 


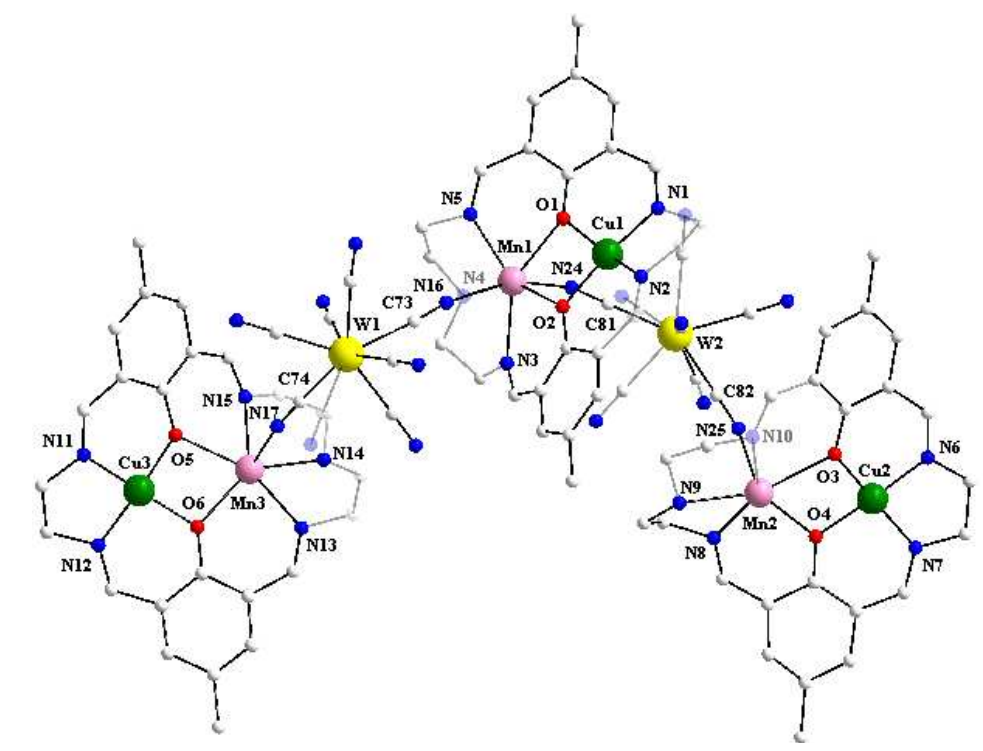

Figure S1. View of the asymmetric unit of $\mathbf{1}$ along with the atom numbering scheme.

Table S3. Results of the SHAPE1 analysis for the $\left[\mathrm{W}(\mathrm{CN})_{8}\right],\left[\mathrm{MnO}_{2} \mathrm{~N}_{5}\right]$ and $\left[\mathrm{CuO}_{2} \mathrm{~N}_{2}\right]$ fragments.

\begin{tabular}{|c|c|c|c|c|}
\hline $\begin{array}{l}\text { Structure } \\
{\left[\mathrm{W}(\mathrm{CN})_{8}\right]}\end{array}$ & SAPR-8* & TDD-8* & JBTPR-8* & BTPR-8* \\
\hline$\left[\mathrm{W} 1(\mathrm{CN})_{8}\right]$ & 0.834 & 1.425 & 1.907 & 1.306 \\
\hline$\left[\mathrm{W} 2(\mathrm{CN})_{8}\right]$ & 1.766 & 0.666 & 2.082 & 1.448 \\
\hline $\begin{array}{l}\text { Structure } \\
{\left[\mathrm{MnO}_{2} \mathrm{~N}_{5}\right]}\end{array}$ & PBPY-7 $7^{* *}$ & COC- $7^{* *}$ & CTPR- $7^{* *}$ & JPBPY-7** \\
\hline$\left[\mathrm{Mn} \mathrm{OO}_{2} \mathrm{~N}_{5}\right]$ & 3.031 & 2.950 & 1.295 & 6.775 \\
\hline$\left[\mathrm{Mn}^{2} \mathrm{O}_{2} \mathrm{~N}_{5}\right]$ & 1.362 & 4.332 & 3.511 & 4.741 \\
\hline$\left[\mathrm{Mn} \mathrm{O}_{2} \mathrm{~N}_{5}\right]$ & 1.327 & 4.372 & 2.869 & 4.674 \\
\hline $\begin{array}{l}\text { Structure } \\
{\left[\mathrm{CuO}_{2} \mathrm{~N}_{2}\right]}\end{array}$ & \multicolumn{2}{|c|}{ SP-4 ${ }^{* * * *}$} & \multicolumn{2}{|c|}{$\mathrm{T}-4^{* * *}$} \\
\hline$\left[\mathrm{Cu} \mathrm{O}_{2} \mathrm{~N}_{2}\right]$ & & \multicolumn{2}{|c|}{22.743} \\
\hline$\left[\mathrm{Cu} 2 \mathrm{O}_{2} \mathrm{~N}_{2}\right]$ & \multicolumn{2}{|c|}{1.512} & \multirow{2}{*}{\multicolumn{2}{|c|}{$\begin{array}{l}23.200 \\
23.211\end{array}$}} \\
\hline$\left[\mathrm{Cu} 3 \mathrm{O}_{2} \mathrm{~N}_{2}\right]$ & \multicolumn{2}{|c|}{1.468} & & \\
\hline
\end{tabular}

"SAPR-8, $D_{4 d}$ Square antiprism; TDD-8, $D_{2 d}$ Triangular dodecahedron; JBTPR-8, $C_{2 v}$ Biaugmented trigonal prism J50; BTPR-8, $C_{2 v}$ Biaugmented trigonal prism

${ }^{* *}$ PBPY-7, $D_{5 h}$ Pentagonal bipyramid; COC-7, $C_{3 v}$ Capped octahedron; CTPR-7, $C_{2 v}$ Capped trigonal prism, JPBPY-7, $D_{5 h}$ Johnson pentagonal bipyramid J13

${ }^{* * *}$ SP-4, $D_{4 h}$ Square, T-4, $T_{d}$ Tetrahedron 


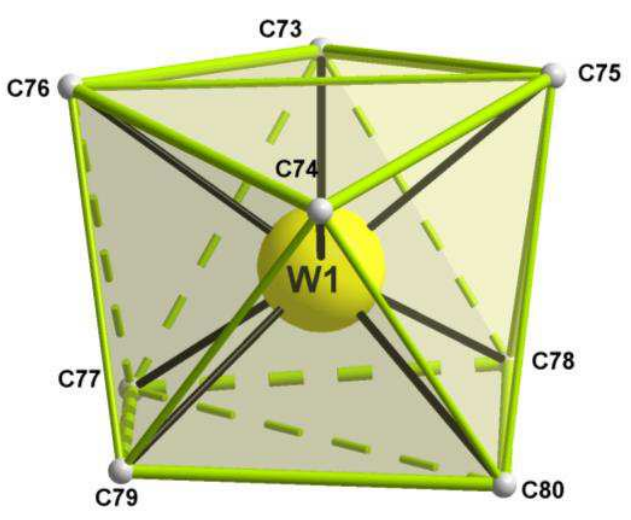

a)

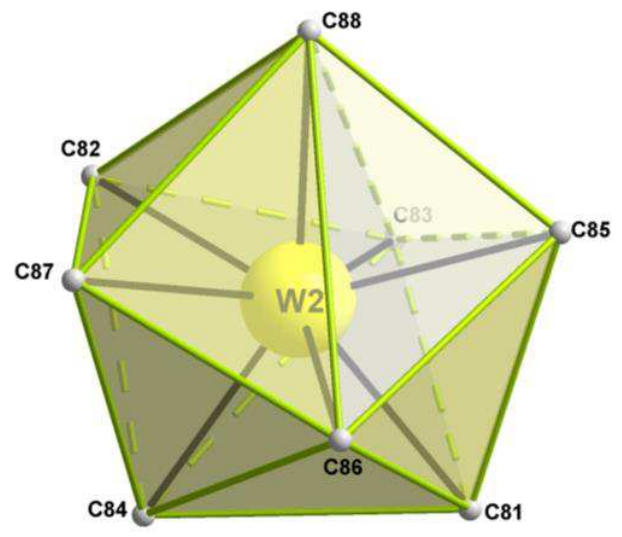

b)

Figure S2. Coordination sphere of the $\mathrm{W}$ metal ion illustrating the distorted square antiprism coordination geometry for W1 and trigonal dodecahedron for W2 in $\mathbf{1}$.

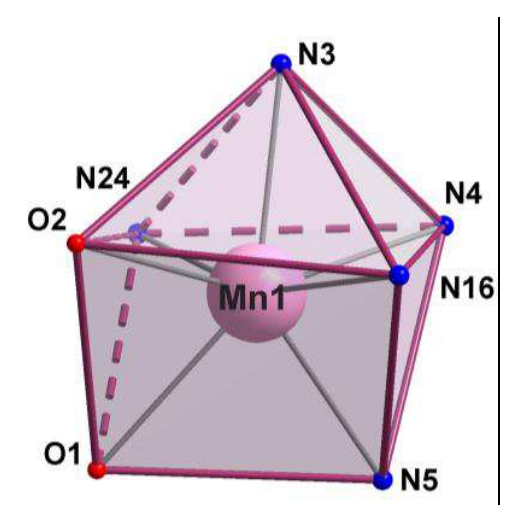

a)

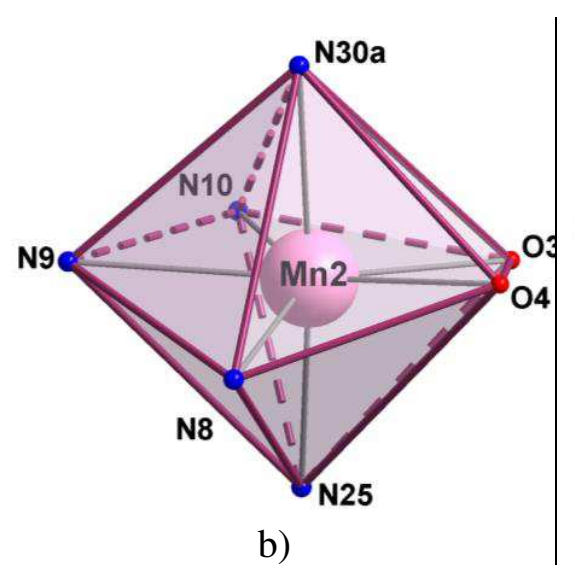

b)

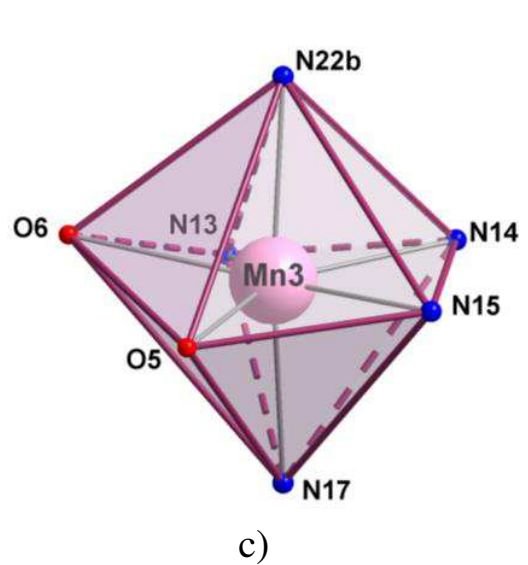

c)

Figure S3. Coordination sphere of the Mn1, Mn2 and Mn3 sites in 1. A distorted monocapped trigonal prism could best describe the coordination environment of Mn1 (Figure S3a). The imino $\mathrm{N} 3$ atom occupies the capping position of the rectangular face (O2-N24-N4-N16). The geometry of the $\mathrm{Mn} 2$ site is a distorted pentagonal bipyramid, with the pentagonal plane formed by $\mathrm{O} 3, \mathrm{O} 4$ phenoxido, N8, N10 imino, and N9 amino atoms, which belong to the second compartment of the organic ligand, the apical positions being occupied by cyanido nitrogen atoms, N25 and N30a (Figure S3b). The Mn2, N25 and N30 $a$ atoms are almost collinear, the N25-Mn2-N30 $a$ angle being of 175.1(3) ${ }^{\circ}$. where N16 and N24 atoms form the diagonal of the capped face. The geometry around Mn3 metal ion could also be described as a distorted pentagonal bipyramid, with N13, N14, N15, O5, O6 atoms, forming the basal plane, and the cyanido N17 and N22 $b$ atoms occupying the apical positions (Figure S3c). Symmetry codes: $a=1 / 2+x, 1 / 2-y, z ; b=-1 / 2+x, 1 / 2-y, z$ 


\section{Supramolecular interactions}

The water molecules establish hydrogen bonds with the nitrogen cyanido atoms from two neighboring chains, Figs S4 and S5.

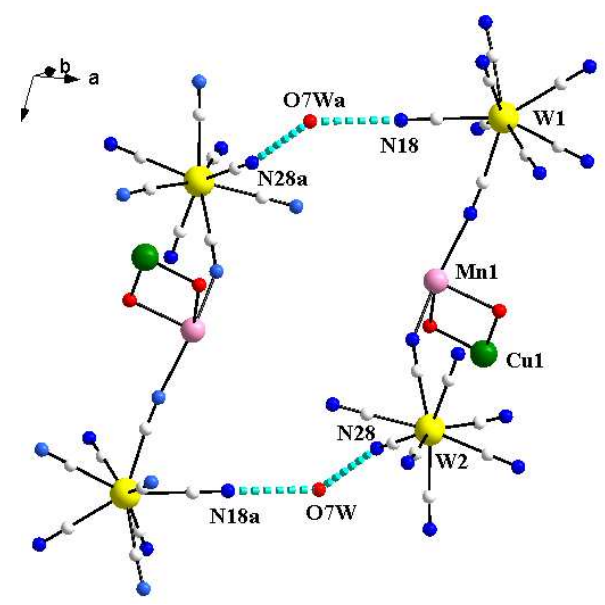

Figure S4. Supramolecular interactions: fragment of the crystal structure of $\mathbf{1}$ highlighting the hydrogen bond network established between the water molecules and the heterotrimetallic chains. The water molecules establish hydrogen bonds with the nitrogen cyanido atoms from two neighboring chains shown in Figure S5. Symmetry codes: $a=1-x,-y, 2-z$.

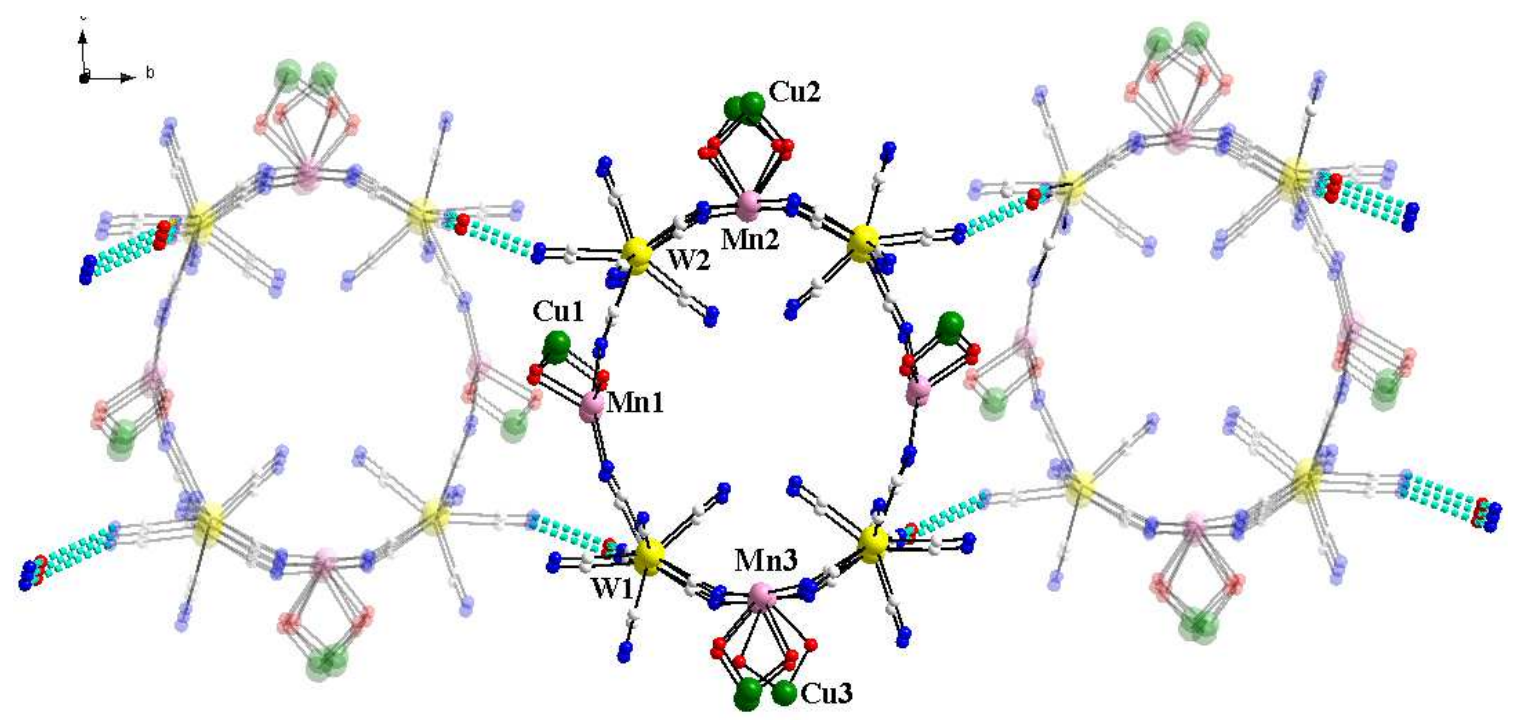

Figure S5. Supramolecular interactions: chains running along $a$ axis, connected by hydrogen bonds shown in Figure S4. 


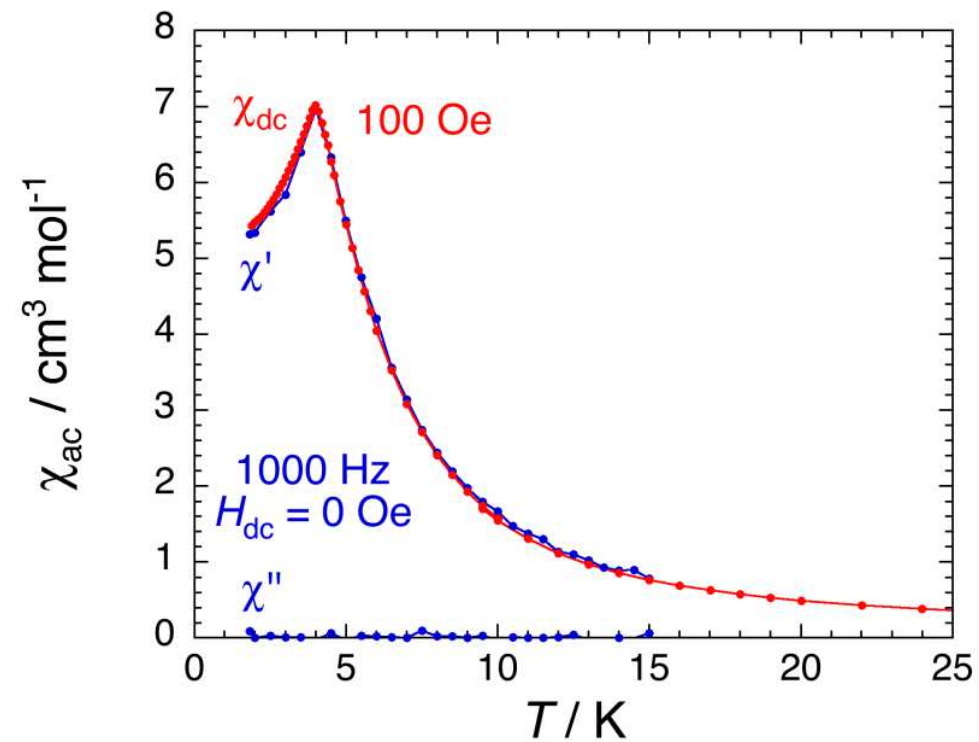

Figure S6. Temperature dependence in zero-dc field of the in-phase and out-of-phase components of ac susceptibility (blue dots) for $\mathbf{1}$ between 25 and $1.85 \mathrm{~K}$ at $1000 \mathrm{~Hz}$ with an amplitude of the ac field of 3 Oe. For comparison, the temperature dependence of the dc susceptibility at 100 Oe is shown in red.

\section{References}

1. H. Okawa, J. Nishio, M. Ohba, M. Tadakoro, N Matsumoto, M. Koikawa, S. Kida, D. E. Fenton, D.E., Inorg. Chem. 1993, 32, 2949.

2. M. Pascu, F. Lloret, N. Avarvari, M. Julve, M. Andruh, Inorg. Chem. 2004, 43, 5189.

3. D. Visinescu, J.-P. Sutter, C. Ruiz-Pérez, M. Andruh, Inorg. Chim. Acta 2006, 359, 433.

4. J. R. Withers, D. Li, J. Triplet, C. Ruschman, S. Parkin, G. Wang, G. T. Yee, S. M. Holmes, Polyhedron, 2007, 26, 2353. 